\title{
The Impact of Climate Change on Fragility Index: Based on Fuzzy Evaluation Model
}

\author{
Xiang-fei DU*, Yi-xiao ZHANG \\ The Second Campus of North China Electric Power University \\ Baoding, Hebei, China \\ ${ }^{*}$ Corresponding author
}

Keywords: AHP; Fuzzy Evaluation; Climate Changing; Fragility Index.

\begin{abstract}
All along, climate change has a huge impact on the development and stability of each country. It is also closely linked with the country's fragility and even causes political ten-sions between countries. Therefore, finding the impact of climate change on the national fragility is very important for the development of China. This article focuses on how to set up a model to assess the impact of climate change on national fragilities and how to mitigate the effects of climate change through human intervention. First of all, three indicators have been chosen that measure the country's fragility: economic factors, natural resource factors and safety factors, combined with the annual average annual precipitation to measure the impact of climate change. Through the mod-eling, a mathematical model of the relationship between the three factors and annual mean precipitation has been obtained. Based on these three factors, a fuzzy evaluation model based on analytic hierarchy process has been established to get an evaluation system of national vulnerability. Next, the effectiveness of the model across continents and cities has been tested and the conclusion is drawn that this model has a good prediction effect in the city, but more precise adjustments are needed on the continents.
\end{abstract}

\section{Introduction}

The impact of global climate change on the international community is an interdisciplinary and comprehensive issue. From ancient times to the present, climate change has affected the living conditions and quality of life of human society all the time, thus indirectly or directly affecting the stability of the situation within the country and the political relationship between countries.

The climate and the environment are unpredictable. Environmental issues do not necessarily directly lead to international conflicts, but they are important factors in triggering international conflicts. Climate change can lead to political instability including regional conflicts or even international conflicts in the two ways. One is that the resources for survival change, such as water, oil, food and other resources, and the second is the survival condition changes including air pollution, land desertification, sudden floods and mudslides.

The carrying capacity of the Earth's ecosystem is on the verge of extremes, and the climate change may suddenly accelerate the collapse of regional ecosystems. If this trend does not change, countries in areas with ecosystem collapse will become aggressive because they do not have access to living resources. Violence and division are bound to be unavoidable. If climate change makes a certain area no longer suitable for human survival, it will inevitably lead to a large number of environmental refugees flooding into neighboring countries. Social problems such as poverty, unemployment, and crime will be linked and even terrorism will be bred, making an originally stable country an unstable place.

The effects of growing droughts, shrinking glaciers, changes in plant as well as in animal species and climate change such as sea level rise have been emphasized and varied by region. It is well believed that the net damage costs of climate change can be provided by the Intergovernmental Panel on Climate Change. Many of these effects will alter human lifestyles and could lead to the weakening and collapse of social and governmental structures. Therefore, unstable governments probably bring 
their states fragility.

A fragile state refers to the country whose government is unable or unwilling to provide the people with the basic essential of life. In a fragile state, due to climate shocks such as natural disasters, reduced arable land, unpredictable weather and rising temperatures, its population is exposed to hazard. Non-sustainable environmental practices, migration, and resource shortages, which are common in developing states, may further aggravate states with weak governance. It can be proved that the drought has further aggravated the vulnerability of Syria and Yemen. Environ-mental pressure by itself does not necessarily trigger violent conflict, but there is evidence that it can easily lead to violent regional conflicts when it is combined with weak governance and social fragmentation. This confluence can enhance a spiral of violence, typically along latent ethnic and political divisions. The primary notations used in this paper are listed in Table 1.

Table 1. Notations

\begin{tabular}{l|l}
\hline Symbol & Definition \\
\hline$T$ & Temperature (Celsius) \\
\hline$P$ & Precipitation (Mm) \\
\hline$A A T$ & Annual Average Temperature (Celsius) \\
\hline$A P$ & Annual Precipitation (Mm) \\
\hline$G D P$ & Gross Domestic Product per capita (Dollar) \\
\hline$P R$ & Poverty Rate \\
\hline$F R P C$ & Freshwater Resources per capita (Cubic meter) \\
\hline$F P P C$ & Food Production per capita (Ton) \\
\hline$V C$ & Vegetation Coverage \\
\hline$R O U C$ & Rate of Unheathy Children \\
\hline$E W$ & The Proportion of the Population Affected by Extreme Weather \\
\hline$M R$ & Migration Rate \\
\hline$\varepsilon$ & Uncertainty \\
\hline
\end{tabular}

\section{The Fragility Index Model}

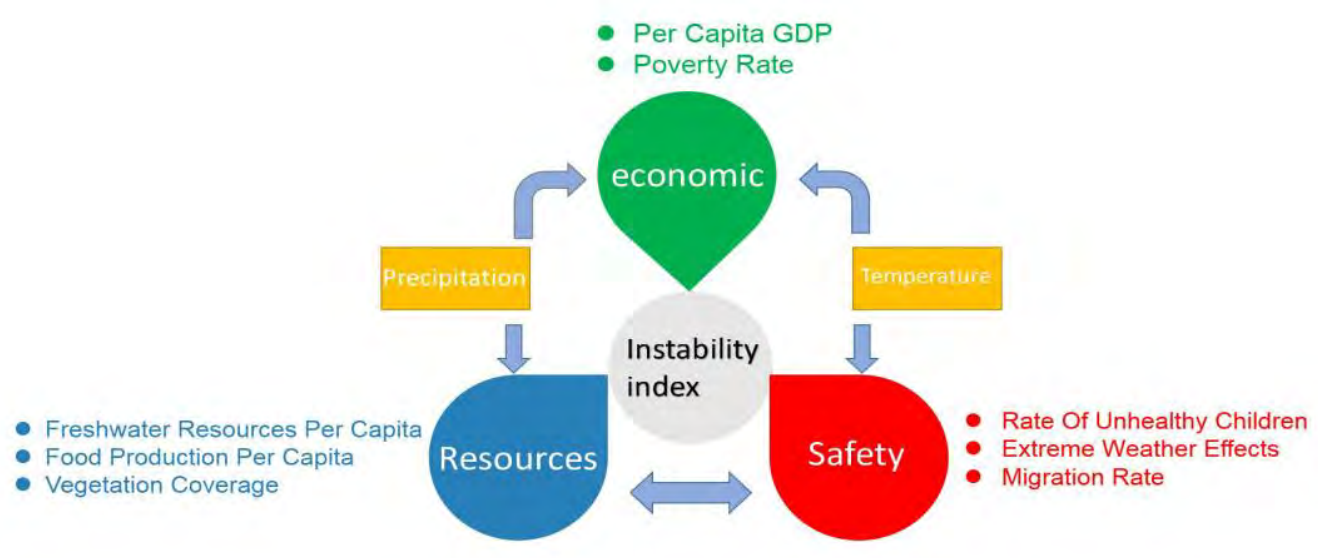

Figure 1. Indicator Diagram

We have built a model of assessment that uses climate change as a variable. Climate change is defined as the change in the atmosphere caused by direct or indirect human activity that alters the composition of the Earth's atmosphere in addition to the natural variability of climate observed during similar times. (Reference UN Framework Convention on Climate Change) Climate change is mainly reflected in the greenhouse effect, that is, its temperature change, and we choose the annual average 
temperature as the measure of its standard. Climate change can cause catastrophic floods or droughts in the country, which can affect its annual precipitation changes, so we have chosen annual precipitation as its quantitative indicator. In order to reflect the changing climate, we have determined the average temperature and precipitation over many years in a country as its climate-invariant standard. The impact of climate change is reflected by the comparison of temperature and precipitation over many years with a single year.

\subsection{Economic Impact}

For a country, the economy is a measure of its national strength. The more stable and less fragile a country is, the less likely it is to be affected by climate change. That is to say this state can also have better economic strength to deal with the impact of climate change. Therefore, we choose the per capita GDP of the state as an indicator of the degree of fragility of the country.

Next we try to measure the impact of climate change on economic factors. As climate change affects the country's fragility primarily through its impact on the national economy, in addition the poverty rate is affected by the national economy. Therefore, we measure the relationship among climate change, precipitation, atmospheric temperature and per capita GDP. By consulting literatures, the per capita GDP is in a linear relationship with precipitation and atmospheric temperature, therefore, the model is:

$$
G D P=a \times A A T+b \times A P+c+\varepsilon
$$

\subsection{Resource Impact}

Climate change has a great impact on basic resources. Per capita freshwater resources are mainly related to precipitation, while per capita food production is affected by temperature and precipitation in climate change. Vegetation coverage represents the future impact of climate change and we do not consider short-term projections of the model. So we draw the relationship between freshwater resources and rainfall:

$$
F R P C=a \times A P+b+\varepsilon
$$

By consulting literatures, we are able to obtain relationship model of per capita grain yield with rainfall and atmospheric temperature [2]:

$$
F P P C=a \times A A T+b \times A P+c+\varepsilon
$$

\subsection{Safety Factors}

Climate change can alter ecological conditions in a country, rising numbers of mosquitoes at increased temperatures and promoting spread of infectious dis-eases can lead to an increase of the ill health of children. So climate change will indirectly affect children's health. The occurrence of extreme weather is directly linked to climate change, so it can directly affect civil safety through temperature and precipitation. We have defined the model to reflect the climate change impact on national security, as shown in the formula below. Population migration is affected by many factors, such as economics variables, climate and war. These factors are also affected by the climate. As a result, the rate of migration is indirectly affected by the climate, so we will not conduct modeling analysis here.

The occurrence of extreme weather is directly linked to climate change, so it can directly affect civil safety through temperature and precipitation. What is known for us, whether the temperature or precipitation, too high or too low will cause extreme weather. Therefore, we have defined the model to reflect climate changes impact on national security, the formula is showed below:

$$
E W=a \times(T-\overline{A A T})^{2}+b \times(P-\overline{A P})^{2}+c+\varepsilon
$$

\section{Model Establishment}

Fuzzy comprehensive evaluation is based on fuzzy mathematics. Application of the principle of 
fuzzy relationship synthesis with some of unclear boundaries is not a quantitative factor, but a comprehensive evaluation of a method [3]. In the comprehensive evaluation of national vulnerability, a large number of complex phenomena and interactions of many factors are involved, and there are a lot of ambiguities and ambiguities in the evaluation [4]. Therefore, in the comprehensive evaluation, fuzzy comprehensive evaluation method is of-ten used to quantify [5], to assess the national vulnerability level, and achieved good results. However, the determination of weight requires knowledge and experience of experts, which has certain defects. Therefore, this paper uses analytic hierarchy process (AHP) to determine the weight coefficient of each index. Make it more reasonable, more in line with the objective reality and easy to quantify, so as to improve the accuracy of fuzzy comprehensive evaluation results.

Based on the eight basic indicators we have chosen, we collect data from many representative countries, such as war-torn Afghanistan, drought-ridden Egypt, economically developed Finland, etc. According to our new model, to judge the fragility of a country, we must first judge the merits of each of its indicators. According to the evaluation criteria, we determine the sub-vector of each indicator judgment. After determining each sub-vector judgment, we get the evaluation matrix R1, R2 and R3 for the single factor, and then through the Matlab algorithm, we get the fuzzy relation sub-matrix:

$$
Q_{i}=w_{i} \times R_{i}
$$

Finally we get fuzzy relation matrix $\mathrm{Q}$. Through the weight coefficient matrix $\mathrm{W}$ and fuzzy relation matrix $\mathrm{Q}$, we get the final judgment vector $\mathrm{S}$ :

$$
S=W \times Q
$$

\section{Example Analysis and Evaluation}

In order to verify our model is reasonable, we choose Finland as an example to judge its fragility index. Through the judgments of various indicators in Fin-land, we can obtain the evaluation matrix $R_{1}, R_{2}$ and $R_{3}$ :

$$
\begin{aligned}
R_{1} & =\left(\begin{array}{lll}
0 & 0 & 1 \\
0 & 0 & 1
\end{array}\right) \\
R_{2} & =\left(\begin{array}{ccc}
0 & 0 & 1 \\
0 & 0.9 & 0.1 \\
0.7 & 0.3 & 0
\end{array}\right) \\
R_{3} & =\left(\begin{array}{lll}
0 & 0 & 1 \\
0 & 0 & 1 \\
0 & 0 & 1
\end{array}\right)
\end{aligned}
$$

Then, the evaluation matrix is introduced to the fuzzy evaluation algorithm based on AHP by using Matlab. At last, we get the proportion of each attribute $S=(0.0252,0.159,0.8209)$. According to the principle of maximum membership, Finland's stable ratio is as high as 0.8 , so it is a very stable country. According to the actual situation, Finland belongs to the ranks of developed countries, its official commentary on the site is also very high, the economy is developed, and the resources are rich, therefore, our model is accurate and practical.

\section{Conclusion}

In this paper, we examined the impact of climate change on national fragility and established a model for assessing national fragility by modeling the impact of climate change on national economic, resource and safety factors. We use a fuzzy evaluation model based on analytic hierarchy process to 
determine the weight proportion of each of the three factors. After evaluating each index, the evaluation sub-matrix is obtained, and final fuzzy evaluation set can be obtained by bringing it into the fuzzy evaluation algorithm. After setting up the model we chose Finland for testing. Finland is fully compliant and shows that our model is perfect. But in the practical significance, further improvement and exploration are still needed. In order to adapt to decisions and measures, we must use other methods together to simulate future climate scenarios. It is hoped that this article can play a role in encouraging the study of climate change on national fragility, and also hope that the research in this field can be developed and perfected.

\section{References}

[1] Changyi Liu, Wei He. Research on the Relationship between Climate Change and Economic Growth [J]. Journal of Tianjin University (SOCIAL SCIENCE), 2016: 5. (In Chinese)

[2] Yun Meng. Impact of Climate Change on International Grain Trade [J]. Wuhan University of Technology, 2010. (In Chinese)

[3] Yong-hong Hu, Si-hui He. Comprehensive evaluation method [M]. Beijing: Science Press, 2000: 28-29. (In Chinese)

[4] Zuo-Yong Li, Jing Ding and Li-hong Peng. Principle and Method of Environmental Quality Assessment [M], Beijing: Chemical Industry Press, 2004, pp. 69-133. (In Chinese)

[5] Lin Zhang. Analysis and Research on the Evaluation System of Univer-sity Environmental Quality [J]. Gansu Science and Technology, 2006, Vol. 22 (12), pp. 120-121. (In Chinese) 